\title{
Profile of elderly patients presented with psychosocial problems in Ibadan
}

\begin{abstract}
Background: The study reviewed the profile of elderly patients presented with psychosocial problems in Ibadan. The study $x$ rayed the psychosocial interventions of medical social workers and what had been their impact on the recovery of the elderly patients.

Methods: The study was conducted at the Chief Tony Anenih Geriatric Centre, University College Hospital (UCH), Ibadan. The study reviewed the elderly patients based on the presented psychosocial problems at the medical social services unit of the centre. 160 elderly patients were seen at the centre after been referred by geriatric physician of the centre between the period of four (4) years. The research instrument was "Health status", Psychological and Social Well being and Chi square statistics was used to assess association between categorical variable. $\mathrm{P}$ values of significance would be set at $\mathrm{P}<0.05$.

Results: More than half of the elderly patients presented with psychosocial problems are between ages $66-70$ years are $44.5 \%$ (Male) and $41.8 \%$ (female). A little more than half of the respondents are unemployed 40.7(male) and 25.4\% (Female). The result also showed a significant association between health condition and gender of the elderly $(\mathrm{X} 2=18.234, \mathrm{p}=0.00)$ psychological problems was associated with gender of the elderly $(\mathrm{X} 2=23.388, \mathrm{p}=0.00)$ and social problem was also associated with gender of the elderly $(\mathrm{X} 2=57.931, \mathrm{p}=0.00)$.

Conclusion: Poor social economic status among the respondents had a negative impact on their health status as well as their health seeking behavior. The importance of emotional support, economic and information support can be deduced from the fact that spending money or giving information as to health and source of better income does not solve the problem of the elderly because these aged entities also need love, care, affection and a feeling of belongingness. Lack of social support for the aged causes in them depression, anxiety and psychosomatic symptoms because they feel unwanted. There is need to strategize implementation of Geriatric Health Insurance Scheme, recreational and rehabilitation facilities for the elderly within the hospital and their community is also very important to improve their physical, social and psychological well being.
\end{abstract}

Volume I Issue I - 2017

Adeleke RO, Adebowale TO, Oyinlola O
University College Hospital, Nigeria

Correspondence: Oyinlola O, University College Hospital, Ibadan, Nigeria, Email oluwagbemiga.oyinlola@yahoo.com

Received: October 31, 2017 | Published: March 17, 2017

\section{Introduction}

The world population has never been as mature as now. Currently, the number of people aged 60 and over is more than 800 million. Projection indicates that this figure will increase to over two billion in 2050. People aged 60 can now expect to survive an additional 18.5 to 21.6 Years. ${ }^{1}$ Soon the world will have a higher number of older adults than children. Contrary to common sense perceptions, the majority of older people live in low and middle income countries, and some of the fastest rates of ageing are occurring in these areas. ${ }^{2}$

The United Nations uses the benchmark of 60 years of age or above to refer to older people. ${ }^{1}$ However, in many high-income countries, the age of 65 is used as a reference point for older persons as this is often the age at which persons become eligible for old age social security benefits. ${ }^{2}$ This higher age category is less appropriate to the situation in developing countries including Africa where life expectancy is often lower than that in high income countries.

Older adults face special health challenges. Many of the very old lose their ability to live independently because of limited mobility, frailty or other physical or mental health problems and require some form of long term care. Early on, in the beginning of the millennium, it became clear in developed countries that about $20 \%$ of adults aged 55 and over suffer from a mental disorder. ${ }^{3}$ Subsequently, global statistics showed this to be an almost universal psychological and social problem. ${ }^{4}$ Psychosocial problems of older adults are under identified by health care professionals and older people themselves, and older people are often reluctant to seek help. Nigeria is culturally heterogeneous with over 350 ethnic linguistic groups, with the predominant ones being the Hausa of the North. As the most populous country in Africa, Nigeria currently has the highest number of aged or elderly people in Africa.

Population ageing is expanding worldwide including developing countries like Nigeria. The percentage of elderly population has increased from $4.6 \%$ in 2001 to $8.13 \%$ in 2011 . With the largest population in Africa and the ninth in the world, it is estimated that by the year 2025 the population of Nigerians aged 60 and above will constitute 6 percent of the entire population as the projected population Table 1 below. 
Table I presented by the United Nations Population Division, (2005), there is the potential for a rapid growth rate of the older population in coming years, with a lower growth rate among the younger population. Based on the findings of the National Census conducted in 2006, the National Population Commission confirmed an increase in the percentage and the number of those aged 60 years and above.

\begin{tabular}{lllllll}
\hline & \multicolumn{2}{l}{$\begin{array}{l}\text { Population 60+ (\% of } \\
\text { total population) }\end{array}$} & \multicolumn{2}{c}{ Population 60+(Millions) } \\
Region & $\mathbf{2 0 0 5}$ & $\mathbf{2 0 2 5}$ & $\mathbf{2 0 5 0}$ & $\mathbf{2 0 0 5}$ & $\mathbf{2 0 2 5}$ & $\mathbf{2 0 5 0}$ \\
\hline West Africa & 4.7 & 5.5 & 9 & 12 & 21.8 & 51.6 \\
$\begin{array}{l}\text { Southern } \\
\text { Africa }\end{array}$ & 6.6 & 10.6 & 12.8 & 3.4 & 5.2 & 5.95 \\
$\begin{array}{l}\text { Middle } \\
\text { Africa }\end{array}$ & 4.8 & 4.4 & 6.6 & 4.9 & 7.6 & 17.6 \\
East Africa & 4.5 & 4.9 & 7.8 & 12.7 & 20.8 & 47.8 \\
& & & & & & \\
Nigeria & 4.9 & 6 & 9.9 & 6.4 & 11.5 & 25.5 \\
\hline
\end{tabular}

The ageing of populations in African nations such as Nigeria is unfolding in a context of entrenched economic strain ${ }^{5}$ and there is a growing concern about the threat of poverty facing people in old age (HAI, 2002). The vast majority of older persons, having worked in the informal sector, have no access to any formal income security protection and the same applies to days working age population (of which typically $80 \%$ or more are in the informal sector. ${ }^{5}$ The insurance based pension schemes that presently exist in most states typically cover only the tiny minority of those in the public and large formal private sector. ${ }^{6}$

This report portends a major change in the age structure of Nigerian society. The report revealed that, in the coming years, the ageing population is expected to increase in numbers and life expectancy rates will gradually increase with significant social and economic implications to the individuals and the Nigerian government. For example, the old age dependency ratio is not high at present (at least compared with the developed nations) but it will increase in the coming years.

These are due to the changing societal norms young generation is living away from parental home as well as for family business for their livelihood. Hence, it is difficult for elderly to change homes and get adjusted to new place. ${ }^{7}$ Apart from this because of more and more working women, their traditional role of care giver of the elderly is abandoned. Besides, our social culture is also being broken by the changing context of the world, desire for a small family, poverty and urbanization process. In such circumstances, the society seems to have empathized the problems and needs of the elderly and hence have attempted, though not sufficient, to ease their life. ${ }^{8}$

The role of Medical Social Workers cannot be overemphasized as they help diffuse the sense of crisis for family members by assisting in health care planning, discharging planning and by ensuring that the elderly patient and their relatives are included in decision making. Social workers also work on short term therapies as part of intervention programmes for the aged who are distraught and family members as a result of an unwelcome diagnoses or bereavement. The study will examine all the aspects of "Health status", "psychological and social well being" of the elderly to reflects the multidimensional nature of psychosocial problems of the elderly presented at the Geriatric Centre, in Ibadan. The study, first of its nature had the objectives of comparing the psychosocial problems of the elderly attending the Chief Tony Anenih Geriatric Centre, University College Hospital, Ibadan.

\section{Older adults and its presenting psychosocial problems}

Old age consists of ages nearing or surpassing the life expectancy of human beings, and thus the end of the human life cycle. Euphemisms and terms for old people include, old people (worldwide usage), seniors (American usage), senior citizens (British and American usage), older adults (in the social science), the elderly, and elders (in many cultures including the cultures of aboriginal people) (National Aging Institute, 2014).

Old people often have limited regenerative abilities and are more prone to disease, syndromes, and sickness than younger adults (Pew Research Centre, 2014). The organic process of ageing is called senescence, the medical study of the aging process is gerontology and the study of diseases that afflict the elderly is geriatrics (National Ageing Institute, 2014). The elderly also face other social issues such as retirement, loneliness, and ageism. Gerontologists have recognized the very different conditions that people experience as they grow older within the years defined as old age. In developed countries, most people in their 60s and early 70s are still fit, active, and able to care for themselves. ${ }^{9}$ However, after 75, they will become increasingly frail, a condition marked by serious mental and physical debilitation (Help Age International, 2011).

Therefore, rather than lumping together all people who have been defined as old, some gerontologists have recognized the diversity of old age by defining sub groups. One study distinguishes the young old (60 to 69), the middle old (70 to 79), and the very old (80+) Forman, Berman and McCabe, (2012). Another study's sub-grouping is young old (65 to 74), middle old (75-84), and oldest old (85+) Help Age International, (2011). A third sub grouping is "young old" (65-74), "old" (74-84), and "old-old" (85+) (Help Age International, 2011). The distinguishing marks of old age normally occur in all five senses at different times and different rates for different persons (Help Age International, 2011). In addition to chronological age, people can be considered old because of the other three dimensions of old age. For example, people may be considered old when they become grandparents or when they begin to do less or different work in retirement. Psychological Problems of the elderly.

\section{Adaptable}

describes most people in their old age. In spite the stressfulness of old age, they are described as "agreeable" and "accepting." However, old age dependence induces feelings of incompetence and worthlessness in a minority. ${ }^{9}$

\section{Depression}

According to Cox, Abramson, Devine,${ }^{10}$ old age is a risk factor for depression caused by prejudice (i.e., "deprejudice"). When people are prejudiced against the elderly and then become old themselves, their anti elderly prejudice turns inward, causing depression. "People with more negative age stereotypes will likely have higher rates of depression as they get older'. ${ }^{11}$ 
Old age depression results in the over 65 population having the highest suicide rate, ${ }^{9}$ depression is the most prevalent mental health problem among older adults. It is associated with distress and suffering and can lead to impairments in physical, mental, and social functioning. The presence of depressive disorders often affects the course and complicates the treatment of other chronic diseases. Older adults with depression visit the doctor and emergency room more often, use more medication, incur higher outpatient charges, and stay longer in the hospital. Although the rate of older adults with depressive symptoms tends to increase with age, depression is not a normal part of growing older. ${ }^{11}$

Social factors often underlie depression in older persons, especially losses, difficulties in socialization which lead to isolation and sometimes even boredom after retirement. ${ }^{12}$ The risk of suicide is very high among older men in almost all cultures. In the majority of cases depression in older persons is a treatable condition. As with younger people, treatment consists of a combination of antidepressant drugs and supportive counselling or other forms of psychotherapy. It is also important to rule out physical causes of depression and avoid other treatments able to cause depression. ${ }^{13}$

\section{Anxiety}

Panic and phobias disrupt the lives of $10 \%$ of older persons. ${ }^{13}$ Fear is a normal emotion, but sometimes it gets out of control and interferes with the ability to do even simple things. Anxiety is also often a sign of depression in older people and can amplify the physical symptoms related to low mood. Cognitive behavioural therapy and drug treatments, including some which work on both anxiety and depression, can also be useful. ${ }^{14}$

Fear of crime in old age, especially among the frail, sometimes weighs more heavily than concerns about finances or health and restricts what they do. The fear persists in spite of the fact that old people are victims of crime less often than younger people.

\section{Dementia}

Is a general term for memory loss and other intellectual abilities serious enough to interfere with daily life. Its prevalence increases in old age from about $10 \%$ at age 65 to about $50 \%$ over age $85 .^{15}$ Alzheimer's disease accounts for 50 to 80 percent of dementia cases. Demented behavior can include wandering, physical aggression, verbal outbursts, depression, and psychosis. ${ }^{16}$

Unfortunately, there is a lack of awareness and understanding of dementia in most countries. This affects the support for those concerned in a number of ways. Low awareness levels contribute to stigmatization and isolation. Poor understanding creates barriers to timely diagnosis and to accessing ongoing medical and social care, leading to a large gap in treatment. Lack of awareness also takes its toll on the resilience of the family unit and increases financial and legal vulnerability. At a national level, the lack of awareness and lack of infrastructure for providing good and early support increase the likelihood of high costs in supporting increased dependence and morbidity. Although no treatments are currently available to cure dementia, there is much that can be offered to support and improve the lives of all people concerned (WHO, 2012 \& American Association for Geriatric Psychiatry, 2013).

Against the attendant problems of the elderly in the new Nigerian society, the lack of state provision of eldercare in Nigeria requires the family to provide the needs for the survival of the older people. Family members provide food, shelter, clothing drugs and other basic necessities. Children now play the most important role of providing economic security in old age. Older parents live in their adult children's homes and receive care. On the other hand, they support their children in taking care of their grandchildren. When they live in their own homes, grandchildren or other relatives often live with them to give support such washing clothes, running errands, cooking meals and taking general care of the older people's environment.

The decline in the economy, gradually disintegration of the extended family system, unemployment, increasing female employment to complement family income, as well as rural urban migrations, all contribute to the noticeable decline in the level of care provided by the family in recent times. The participation of government at all levels, Federal, Regional (State) and Local Councils, in the provision of services to the older person is minimal. The Nigerian Government and political leaders believe that the provision of care is the responsibility families. ${ }^{17}$

\section{Sociological problems of the elderly}

Traditionally, African societies have been characterized by cultural systems, which gave high status to older people. In the past there was recognition and appreciation of the experience and knowledge that older people offered, which contributed to a sense of integration in the community. In addition the extended family system provided for the social and economic needs of older people. ${ }^{18}$ However, there has been an increasing trend since colonisation to focus on change and modernisation, which has resulted in the higher valuing of the younger generations and looking towards the future, at the expense of maintaining regard for older people, learning from the past and valuing traditions. Over time this has led to the undermining of the roles, status and the welfare of older people who are increasingly becoming socially isolated and psychologically depleted. ${ }^{17}$

The traditional family institution, with its notions of intergenerational commitments, used to care for all family members, including older people. This familial sense of responsibility has been eroded by forces including migration of younger people particularly from rural to urban areas, urbanisation, social and political instability and the impact of the HIV/AIDS pandemic. HIV/AIDS has had a significant social impact upon older people, particularly women. Generally older people can no longer expect to be recipients of family care.

The incidence of death among the middle generation has multiple impacts upon older people. Alongside bereavement, they lose people who might have once been a possible source of external financial support in their old age, and the ongoing income generation responsibility is often coupled with active care responsibilities for adult children and grandchildren, which heighten the financial burden.

The following are some of the sociological problems of elderly which are

\section{Disengagement}

Old age is a period of gradual psychological and social disengagement. By the time the individual retires at 60 or 65 years, most if not all his children would have dispersed either in search of socio economic opportunities or to establish their own homes. Retirement itself, described by Bernard Shaw as threat of eternal 
holidays, would cut him off and isolate him from his old workmates. The position could be compounded by loss of spouse, which commonly happens in the seventh and eighth decades of life. That marks the beginning of solitude and grief and the onset of depression, the intensity of which in some cultures is tempered by substitute spouse. And widowhood could last on the average some fourteen years. This is a stage most individuals increasingly withdraw from intensive emotional attachment to people and objects.

\section{Economic problems}

At socio economic level unless the elderly, having retired, has an alternative and congenial job and unless he has some investments say in savings, company shares, insurance, endowment, etc. proceeds from which he could supplement has pension, his earning will be inadequate to meet his basic needs and that man's poverty which could generate frustration and depression, unless he is fortunate to have someone to run errands for him, help with domestic chores and necessary shopping, he may have to bear by himself these aspects of loads of living. In Yoruba Parlance, 'A ir' eni pe ni pa agba', meaning having no one whom to call for errands slowly kills off the elderly. The elderly have on their hands plenty of time which should be productively filled. Elderly women fare better than men in finding something to do. They mostly engage in helping daughters and sons look after the grandchildren. Having nothing to do could be frustrating. 'When the person again has ample time for choosing a different activity'.

In developing countries, the majority of the people who are economically active work in the informal sector, typically in agriculture, trading or service activities. In these sectors, it is evident that older women and men continue to work until advanced ages. Many older women struggle to balance food production activities with care responsibilities as noted above, for husbands, children and grandchildren. These roles are often performed in conditions of poverty, where there are very limited opportunities to participate in income generating activities (WHO, 2000).

Over time, many developing countries have experienced a decline in the proportion of economically active people in the population employed by the formal sector, because of the stagnation or shrinking of national economies, particularly in Africa. This trend has led to the laying-off formal sector workers for indefinite periods and/ or compulsory early retirement. In many countries in Africa, those fortunate enough to maintain a formal sector job to the official retirement age, often face retirement at 50 or soon after. With the increasing longevity of older people, life after retirement may be long with either a meagre or no pension.

this may be a time of bewildment and frustration because the aims and motives that may be necessary to fill the void may become diffused or even have disappeared money or the relative freedom of an individual to choose what he will do, by being able to afford it with all the emotion and economic consequences that it may bring an influence of considerable intensity.

\section{Cultural pollution}

Traditionally in Nigerian communities, the elderly is highly esteemed and respected both private and public life, in civic and political matters. However, things are changing fast, with importation of foreign culture, chiefly through the media, literature, films and video. Our society is fast changing and we are gradually losing our cultural values. Behaviour of many youth runs counter to the expectations of the aged. Modes of showing respect to the elderly have been thrown overboard, by many. A Yoruba saying goes thus "Aiye ti di aiye eni ti baba re ko gbodo kin i ni iduro, ti nnawo si ni", meaning " the youth whose father would not dare greet the elderly, standing upright now demand that you both greet by shaking hands with each other", that you exchange pleasantries on equal footing! To the elderly, it is a repulsive and disappointing acculturation. The perversion of highly esteemed cultural values, with the introduction of obscene dresses, songs and puzzles and disturbs the elderly who were used only respectable and decent life. such cultural pollution and disorientation as now witnessed is outrageous.

\section{Abuse}

Abuse of older persons is a major societal problem that often goes undetected. Although not a new phenomenon, the speed of population ageing worldwide has given rise to fears that abuse of older persons, too, may increase in its incidence, prevalence and complexity. Globally, the number of cases of elder maltreatment is projected to increase as many countries have rapidly ageing populations whose needs may not be met easily due to resource constraints (WHO Regional Office for Europe, 2011).

Elder abuse is associated with a number of consequences, both for individuals as well as societies. Victims of elder abuse often experience significant distress and may never fully emotionally recover from trauma. The individual may suffer from a growing sense of insecurity, from illness, anxiety or depression. Consequences of elder abuse may be worsened because shame and fear of getting institutionalized may cause reluctance to seek help. Victims of elder abuse are typically torn between the feelings they have for their abusers and their desire to speak up about the abuse. They are also often dependent on their abuser (WHO Regional Office for Europe 2011).

Elder abuse, including neglect seems to lead to higher dependence in performing activities of daily living, increased emergency room visits, higher rates of mortality, and self-destructive behaviours in abused elders which can even result in suicide. For older people, the consequences of maltreatment can be especially serious because their bones are more brittle and convalescence takes longer. At the societal level, abuse is related to higher direct costs related to health care, case detection and staff training, as well as indirect costs related to loss of social capital and the reduced ability of people to productively contribute to society.

\section{Concern of medical social workers in the care of the elderly}

According to ${ }^{19}$ they highlighted the major areas of concern to social workers in the care of the aged which are:

\section{Provision of adequate financial support}

Aged needs steady and adequate income to guarantee security and eliminate fear. They require money not only for feeding and housing but also for health care services. In most elderly health care, the social workers are is on top of this issue through linkages with available resources in the community.

\section{Enhancement of physical and mental health}

Good health is one of the most important factors in the elderly sense 
of well-being. The social workers apply psychosocial approaches to reduce theses effects where total elimination of the effects is not possible.

\section{Ensuring suitable housing}

The major problem of the aged generally is housing. Some elderly cannot afford safe, comfortable housing while those who can afford good housing do not keep the regulations for safety requirement. They live in an unsafe housing facility which is easy that aged are catered for in good housing environment. The see children or relatives of the aged person provide better housing or good communication for them.

\section{Restorative services for those who require institutional care}

The aged in need of institutional care are carefully evaluated by social workers. Institutional care of the aged (e.g care for the elderly in nursing homes) is not encouraged except in such situations as in serious health and mental health problems. The institutional care that is quite restorative encouraged by the social workers for the aged is recreational. This is where the aged come together to talk and have some indoor games that are not energy sapping (e.g Ayo games, checker card, etc) reading of newspapers and magazine and watching television programmes. This is a pursuit of meaningful activity in a way.

\section{Knowledge about laws guiding geriatric care}

The social worker working with the aged must be knowledgably in the existing laws of the land guiding the practice among the aged. The practice must be within the laws. The aged need to be independent to choose the kinds of activities they pursue. They need to make decisions concerning their lives. Social Workers have the responsibility to see that the aged are given these opportunities.

\section{Improving the quality of life}

The aged are caught up in a number of contradictions that do not affect people at earlier stage of life. Because these contradictions are incompatible within the desired quality of life, the aged are caught up in a social problem. Therefore the main goal of social work practice among the aged is to enhance the quality of life and promote the independence and dignity of the aged. The social workers work very closely with the family of the aged since the family is the primary provider of the care for their aged.

\section{Respect for human rights and dignity}

Social work is based on respect for the inherent worth and dignity of all people, and rights that follow from this. The aged are sometimes not respected by the people because of ageism, that is, the notion that old people are no longer useful as they think. Social work does not support this notion. Social workers uphold and defend each person's physical, psychological, emotional and spiritual integrity and well being. In other words, social workers respect the right to self determination, right to make own choices and decisions irrespective of their age, provided this does not threaten the rights and legitimate interests of others.

\section{Collaboration with other care givers}

Social workers work in solidarity with other professional who have interest in the well being of the aged. They, therefore have the obligation to challenge social conditions that contribute to social exclusion, stigmatization or subjugation and to work towards an inclusive society (IFSW, 2004).

\section{Reducing psychological instability}

One of the major psychological factors affecting the aged is psychological instability. The children, and probably the spouse, may not be with the aged and feeling of loneliness (complete empty nest) sets in. the colleagues or mates are almost all dead. The living may not meet as often as before. One or all of these may lead to depression. The social help in reducing repressive feelings by encouraging the aged to visit their children, friends, neighbours, relatives or ask for their assistance to take them out.

\section{Ensuring adequate social support}

There is usually lack of support for most of the aged. This lack may be financial, material, medical, peers and family. observed that a depressed individual, especially an aged has many issues to deal with such as bereavement, especially the loss of a spouse, increased awareness of one's own physical vulnerability i.e that one's own life is limited; and prospect of dependency on others to have one's basic needs met.

\section{Meeting the autonomy need}

The elderly need autonomy supportive relationships and meaningful activity. The elderly who maintain autonomy in such things as managing on their own, having control over how they spend their time and having adequate financial resources adapt well to later years. Social workers ensure that the elderly persons are involved in decisions that affect their daily living. They also make sure that the aged enjoy good supportive relationships from their family, friends and care givers. They see that the aged are engaged in meaningful activities that allow them to experience a sense of achievement and personal growth.

\section{Methodology}

\section{Study Site}

This study was carried out in Ibadan, the capital city of Oyo state. Ibadan is located in the South Western geopolitical zone of Nigeria and has a population of about 3.6million inhabitants (National Population Commission, 2006). The Yoruba tribe is the major predominant ethnic group in Ibadan (NPC, 2006).

The study was conducted at the Chief Tony Anenih Geriatric Centre, University College Hospital (UCH), Ibadan. UCH is a tertiary health institution founded in 1957 as the first teaching hospital in Nigeria, and started has 1000 beds. It has various specialty units and paramedical services with inpatient and outpatient services. University College Hospital, Ibadan has patients referred from all parts of Nigeria and the West African sub region.

The Geriatric Center, University College Hospital, Ibadan is First in West African Sub-Region and was officially commissioned on 17th November, 2012 by the Former Minister of Health Professor Onyebuchi Chukwu. The Centre was endowed by Chief Tony Anenih CFR and clinical services for senior citizens aged 60 years and above commenced on the 13th December, 2012.

The Medical Social Services officially started alongside with other 
clinical services at the Centre to address psychosocial problems of elderly patients presented at the centre.

\section{Method of data collection}

Respondents are older people attending the Chief Tony Anenih Geriatric Centre. The study systematically selected respondents (patients attending the Centre). The study reviewed the profile of elderly patients presented with psychosocial problems at the medical social services unit of the centre between years 2013-2016.

\section{Participants}

Eligible respondents were selected after being registered at the Health Records Section of Centre; they will be assessed and diagnosed by the consultant managing the patient. As matter compliance, psychosocial problems of elderly were a point concern for the geriatric physician. Hence, only patients aged 60 or more were included for the study. The profile of the elderly patient was retrieved from two components.

Firstly, patient's medical record was checked for exclusion criteria The researchers are medical social workers who assessed the elderly patients referred by the geriatric physicians, nurses and other health care professional of the centre. The researchers assessed the elderly patients based on "General Health status", Psychological and Social Well-being" together reflects the psychosocial nature of the elderly patients presented at the medical social services unit. Ethical approval for the study was granted by the Research Ethics Committee of the centre.

\section{Sampling method}

The Geriatric center attends to an average of 1568 new patients monthly. The study purposively selected 160 elderly patients presented with psychosocial problems referred by geriatric physician of the centre.

\section{Data collection}

Instrument: The research instrument were "Health status", Psychological and Social Well being" together reflects the psychosocial nature of the elderly patients presented at the medical social services unit of the centre. The respondent's socio demographic data, family structure.

\section{Consent for the study}

Permission for the study was obtained from the Director, Chief Tony Anenih Geriatric Center of the University College Hospital, Ibadan.

\section{Data analysis}

At the end of the study, the data were entered into a multipurpose computer statistical program, SPSS version Chi square statistics would be used to assess association between categorical variable. $\mathrm{P}$ values of significance would be set at $\mathrm{P} \leq 0.05$.

\section{Results}

Results presented above revealed that, more than half of the respondents presented at the centre are within the ages of 66-70years and they are mostly male while less than $41 \%$ of the female respondents are within the ages of 66-70years, the result also that, less than 5\% of the elderly respondents revealed poor health seeking behaviour of elderly who are ages $85 y$ years and above. About $46 \%$ of the male elderly are Christians by faith, $65.5 \%$ of the female elderly are also Christian by faith, less than $51 \%$ practice the Islamic religion, less than $1 \%$ of the elderly practice the traditional or other types of religion. Less $67 \%$ of the female elderly patients had no formal education, while $38.9 \%$ of the male elderly patient had primary school education, about $5.6 \%$ had both secondary school and post secondary school education and are predominantly male elderly patients. Less than $5 \%$ never married, $44.4 \%$ of the male elderly are married while over $90 \%$ are also married, less than $1.9 \%$ are divorced, over $22.2 \%$ of the male elderly are widowed while $3.6 \%$ of the female elderly are equally widowed, over $25 \%$ of the male elderly are separated while $3.6 \%$ are the female elderly are also separated from their marriage. More than half of the elderly patients presented at the centre are predominantly Yoruba, while less than $5 \%$ are from the Igbo ethnic group. More than $18 \%$ of the elderly are self employed, $13 \%$ are artisans, less than $27 \%$ are farmer, while over $27 \%$ of the elderly presented to the social workers are retirees while over $40 \%$ of the male elderly are unemployed while $25.55 \%$ of the female respondents are unemployed. Over $47 \%$ of the elderly had 0-4children, $70.4 \%$ had about 5-11 children while less than $7 \%$ had more than 12 children. Assessing the major source of income of the elderly, less than $7 \%$ depends on their own personal income, $13 \%$ of the elderly depends on their spouse, over $29 \%$ of the male and $27 \%$ of the female elderly depends on their children/grandchildren for financial support, $54.5 \%$ of the female and $33.3 \%$ of the male elderly depends on other family member/relatives while $16.7 \%$ of male and $14.5 \%$ depends on their friends.

The result presented above revealed that, equal number of elderly patients are seen at the centre with cancer by the medical social worker are a little more than $7 \%(\mathrm{X}=1.64, \mathrm{~S} . \mathrm{D}=2.22)$, while $13 \%$ of the male elderly patients, $12.7 \%$ of the female elderly patient had dementia(X=0.61,S.D1.42). Over $20 \%$ of the male elderly patient and $20 \%$ of the female elderly patient had diabetes $(X=1.84$, S.D $=2.11)$, Over $42 \%$ of the male elderly patient and $38.2 \%$ of the female elderly patient had hypertension $(X=1.25, S . D=1.33)$. Less than $3 \%$ of male ad $3.6 \%$ of the female elderly patient had malnutrition $(X=0.82$, $\mathrm{S} . \mathrm{D}=1.96$ ). More $9 \%$ of the male and $9.1 \%$ of the female elderly patient had schizophrenia $(X=1.53, S . D=1.40)$. About $5.5 \%$ of the female respondents had tooth problem while none of male elderly patients were presented with tooth problem $(X=1.25, \mathrm{~S} . \mathrm{D}=1.61)$. About $3 \%$ of male and $3.6 \%$ of the female elderly patients had other health conditions $(X=0.32, S . D=1.12)$. In the same vein, diabetes and malnutrition took the lead in terms of the magnitude of health condition presented by the elderly followed by cancer, dementia, then schizophrenia, tooth problem and other health conditions. Elderly patients presented with all these health conditions were treated by the geriatric physicians, they are educated about the social implication of their illness by the medical social workers and the need to be drug compliant was emphasised. The result revealed that, $(\mathrm{X} 2=18.234$, $\mathrm{p}=0.00$ ) there was a joint association between the sex and health condition of elderly patients presented at the geriatric centre (Table 2-5).

In view of the above results, $14.8 \%$ of the male and $10.9 \%$ of the female elderly patients were presented with depression $(\mathrm{X}=1.31$, S.D $=1.62), 31.5 \%$ of male and $23.6 \%$ of the female elderly patients were presented with fear and anger( $X=1.81, \mathrm{~S} . \mathrm{D}=2.06)$. More than $48 \%$ of male and $60 \%$ of the female elderly patients experience loneliness/ isolation $(X=1.51$, S.D $=2.06), 5.6 \%$ of male and $5.5 \%$ of female respondents are not compliance with their $\operatorname{drugs}(X=1.51, S . D=1.62)$ 
while $3.7 \%$ of male and $3.6 \%(X=0.93$, S.D $=1.09)$ of the female elderly patients experience other forms of psychological problems which are anguish, stigma, discrimination, violence and abuse. The results presented that, more half of the respondents experience fear, followed by depression and none compliance to drug, then loneliness/isolation while other psychological problems were presented among the elderly presented at the centre. Elderly patients presented with psychological problems were comprehensively counselled using various therapeutic skills of the medical social worker. The medical social workers engage the elderly in group therapy sessions to address the presenting psychological problems of the elderly. The result of the analysis also revealed that, $(X=23.388, p=0.00)$ there was a significant association between sex and psychological problems of elderly patients presented at the geriatric centre, Ibadan.

Table 2 Demographic characteristics of respondents by sex

\begin{tabular}{|c|c|c|}
\hline & $\begin{array}{l}\text { Male } \\
n=54\end{array}$ & $\begin{array}{l}\text { Female } \\
n=55\end{array}$ \\
\hline \multicolumn{3}{|l|}{ Age } \\
\hline 60-65years & $5(9.3 \%)$ & $3(5.5 \%)$ \\
\hline 66-70years & $24(44.4 \%)$ & $23(41.8 \%)$ \\
\hline 7I-75years & I $4(25.9 \%)$ & $15(27.3 \%)$ \\
\hline 76-84years & $8(14.8 \%)$ & $14(25.5 \%)$ \\
\hline $85 y e a r s$ and above & $3(5.6 \%)$ & $0(0 \%)$ \\
\hline \multicolumn{3}{|l|}{ Religion } \\
\hline Christianity & $25(46.3 \%)$ & $36(65.5 \%)$ \\
\hline Islamic & $28(51.9 \%)$ & $19(34.5 \%)$ \\
\hline Traditional/other religion & $\mathrm{I}(\mathrm{I} .9 \%)$ & $0(0 \%)$ \\
\hline \multicolumn{3}{|l|}{ Level of education } \\
\hline No formal education & $27(50 \%)$ & $37(67.3 \%)$ \\
\hline Primary school education & $21(38.9 \%)$ & $17(30.9 \%)$ \\
\hline Secondary school education & $3(5.6 \%)$ & $\mathrm{I}(\mathrm{I} .8 \%)$ \\
\hline Post-secondary education & $3(5.6 \%)$ & $0(0 \%)$ \\
\hline \multicolumn{3}{|l|}{ Marital Status } \\
\hline Single & $3(5.6 \%)$ & $0(0 \%)$ \\
\hline Married & $24(44.4 \%)$ & $50(90 \%)$ \\
\hline Divorced & $\mathrm{I}(\mathrm{I} .9 \%)$ & $\mathrm{I}(\mathrm{I} .8 \%)$ \\
\hline Widowed & $12(22.2 \%)$ & $2(3.6 \%)$ \\
\hline Separated & I4(25.9\%) & $2(3.6 \%)$ \\
\hline \multicolumn{3}{|l|}{ Ethnic Group } \\
\hline Yoruba & $51(94.4 \%)$ & $53(96.4 \%)$ \\
\hline Igbo & $3(5.6 \%)$ & $\mathrm{I}(\mathrm{I} .8 \%)$ \\
\hline Hausa & $0(0 \%)$ & $\mathrm{I}(\mathrm{I} .8 \%)$ \\
\hline Others & $0(0 \%)$ & $0(0 \%)$ \\
\hline \multicolumn{3}{|l|}{ Present Occupation } \\
\hline Artisan & $10(18.5 \%)$ & $4(7.3 \%)$ \\
\hline Self employed & $7(13 \%)$ & $7(12.7 \%)$ \\
\hline Farmer & $10(18.5 \%)$ & $15(27.3 \%)$ \\
\hline Retiree & $5(9.3 \%)$ & $15(27.3 \%)$ \\
\hline Unemployed & $22(40.7 \%)$ & $14(25.4 \%)$ \\
\hline No of children Alive & & \\
\hline
\end{tabular}




\begin{tabular}{|c|c|c|}
\hline & Male & Female \\
\hline & $n=54$ & $n=55$ \\
\hline 5-I Ichildren & $38(70.4 \%)$ & $29(52.7 \%)$ \\
\hline I2children and above & $4(7.4 \%)$ & $0(0 \%)$ \\
\hline \multicolumn{3}{|c|}{ Main source of source of support financially } \\
\hline Self & $4(7.4 \%)$ & $0(0 \%)$ \\
\hline Spouse & $7(13 \%)$ & $2(3.6 \%)$ \\
\hline Children/grandchildren & $16(29.6 \%)$ & $15(27.3 \%)$ \\
\hline Other relatives & $18(33.3 \%)$ & $30(54.6 \%)$ \\
\hline Friends & $9(16.7 \%)$ & $8(14.5 \%)$ \\
\hline
\end{tabular}

Table 3 Health Condition of the elderly by Sex

\begin{tabular}{lllllll}
\hline & Sex & & $\mathbf{X}$ & S.D & $\mathbf{X}_{2}$ & p-value \\
Health Conditions & Male & Female & & & 0 \\
\hline Cancer & $4(7.4 \%)$ & $4(7.3 \%)$ & 1.64 & 2.22 & & 0.01 \\
Dementia & $7(13 \%)$ & $7(12.7 \%)$ & 0.61 & 1.42 & 0 \\
Diabetes & $11(20.4 \%)$ & $11(20 \%)$ & 1.84 & 2.11 & 18.234 & 0 \\
Hypertension & $23(42.6 \%)$ & $21(38.2 \%)$ & 1.25 & 1.33 & & 0.01 \\
Malnutrition & $2(3.7 \%)$ & $2(3.6 \%)$ & 0.82 & 1.96 & 0 \\
Schizophrenia & $5((9.3 \%)$ & $5(9.1 \%)$ & 1.53 & 1.4 & 0 \\
Tooth problem & $0(0 \%)$ & $3(5.5 \%$ & 1.25 & 1.61 & 0 \\
Others & $2(3.7 \%)$ & $2(3.6 \%)$ & 0.32 & 1.12 & & 0 \\
\hline
\end{tabular}

Table 4 Psychological Problems of the elderly

\begin{tabular}{lllllll}
\hline & Sex & & $\mathbf{X}$ & S.D & $\mathbf{X}_{2}$ & P-value \\
Psychological Problems & Male & Female & & & & 0 \\
\hline Depression & $8(14.8 \%)$ & $6(10.9 \%)$ & 1.31 & 1.62 & 23.388 & 0 \\
Fear & $17(31.5 \%)$ & $13(23.6 \%)$ & 1.81 & 2.06 & & 0 \\
Loneliness/isolation & $26(48.1 \%)$ & $33(60 \%)$ & 1.51 & 1.11 & 0 \\
Non-drug compliance & $3(5.6 \%)$ & $3(5.5 \%)$ & 1.62 & 1.21 & 0 \\
Others & $2(3.7 \%)$ & $2(3.6 \%)$ & 0.93 & 1.09 & & 0 \\
\hline
\end{tabular}

Table 5 Social Problems of the elderly

\begin{tabular}{|c|c|c|c|c|c|c|}
\hline \multirow[b]{2}{*}{ Social problems } & \multicolumn{2}{|l|}{ Sex } & \multirow[t]{2}{*}{$\mathbf{x}$} & \multirow[t]{2}{*}{ S.D } & \multirow[t]{2}{*}{$\mathbf{x}_{2}$} & \multirow[t]{2}{*}{ p-value } \\
\hline & Male & Female & & & & \\
\hline Discharge Against Medical Advice & $0(0 \%)$ & $\mathrm{I}(\mathrm{I} .8 \%)$ & 1.22 & 1.47 & & 0 \\
\hline Financial constraints & $25(46.3 \%)$ & $22(40 \%)$ & 1.66 & 1.16 & & 0 \\
\hline Physical assault & $6(11.1 \%)$ & $13(23.6 \%)$ & 1.1 & 1.02 & 57.931 & 0 \\
\hline Poor family support & $23(42.6 \%)$ & $19(34.5 \%)$ & 1.35 & 2.11 & & 0 \\
\hline Others & $33(60 \%)$ & $26(48.1 \%)$ & 1.72 & 2.02 & & 0 \\
\hline
\end{tabular}

Based on the results presented above, about $1 \%(X=1.72, S$. elderly patients experience physical assaults $(X=1.66, S . D=1.16)$, $\mathrm{D}=2.02$ ) of the female elderly patients discharged themselves against medical advice after series of counselling session by the medical social worker and other health care professionals. $46.3 \%$ of male and $40 \%$ of the female elderly patients experience financial more than $42 \%$ of male and $34.5 \%(X=1.10, S . D=1.02)$ of female elderly patients experience poor family support from either their children or extended family relations. About $60 \%$ of male and $48.1 \%$ $(\mathrm{X}=1.22, \mathrm{~S} . \mathrm{D}=1.47)$ of the female elderly patient experience other constraints $(X=1.40, S . D=1.21), 11.1 \%$ of male and $23.6 \%$ of female forms of social problems as a result inadequate or poor social support 
which impaired the quality care being received at the centre. In terms of magnitude of social problems presented by the elderly patients, other social problems like poor or inadequate social support were mostly presented to the medical social worker, followed by financial constraints, then Discharging Against Medical Advice (DAMA) while physical assaults was also presented by the elderly patients. Elderly patients presented with social problems are given financial support, family therapy with patients children and other relative, enrolment of indigent patient into geriatric health insurance plan for one year, home visiting, home assessment, contact tracing for abandoned elderly patients, repatriation of abandoned/neglected elderly patients, linking patients with community resources, discharging planning for admitted elderly patients of the centre. The result revealed that, $(X 2=57.931$, $\mathrm{p}=0.00$ ) there was a joint association between the sex and social problems of elderly patients presented at the geriatric centre.

\section{Discussion}

The study revealed that, there was a significant association between sex and its attend health problems of the elderly presented at the Geriatric Centre, University College Hospital, Ibadan $(p=0.000)$ more than half of the elderly were presented with hypertension and other opportunities infections like dementia, cancer, diabetes, malnutrition, schizophrenia. While less than $5 \%$ of the female elderly patients presented at the centre had tooth problems. The result corroborates with the findings of ${ }^{20}$ that, Hypertension, diabetes and stroke were associated with cosmopolitan treatments, while musculoskeletal conditions were associated with traditional treatments, ${ }^{21}$ supported the findings that, some of the indices to measure old age is the manifestation of diseases. Also the skin becomes drier, thinner and has elastic, wrinkles, visible blood vessels, and pockets of fat under the skin appear as irrefutable evidence of the passage of time. Similarly ${ }^{22}$ also opined that, Pockets of fat settle on various part of the body (most noticeable around the abdomen, but also on the upper arms, the buttocks, the eyelids, and the 'double chin' are mostly presented in older person. Furthermore, in the opined that, in view of the attendant health problems of the elderly; their health needs are met by visiting traditional medicine men and herbalists. The health condition of the elderly is attributed to life styles and environment of the elderly.

There was significant association between sex and psychological problems of the elderly presented at the Geriatric Centre, University College Hospital, Ibadan ( $\mathrm{p}=0.000)$, there was significant presence of loneliness/isolation among the elderly followed by depression, fear, non drug compliance and other psychological problems among the elderly. This is supported by the view of ${ }^{8}$ that, the institutionalized elderly are facing more psychosocial problems as a result disjointed family ties, potential family history of psychological illness ${ }^{23}$ also indicated that, the emotional states like anxiety, depression, loneliness and neglect by family members, lack of self confidence, social isolation are more in old people mostly presented in the hospital settings. In the view of ${ }^{24}$ that, depression and loneliness of institutionalized elderly was higher than that of non-institutionalized elderly due to poor of companionship and consistent communication with their children. Furthermore, showed lower level of subjective well being and more stress in female elderly when compared to male elderly. Oyinlola ${ }^{7}$ opined that, psychosocial problems of the elderly living in home settings showed dependency with educational status, marital status, monthly income, interpersonal relations, and sex and were independent of present job status and type of family of the elderly.

There was a significant association between sex and social problems presented by the elderly at the Geriatric Center, University
College Hospital, Ibadan $(\mathrm{p}=0.000)$, most of the social problems of the elderly presented at the center are discharge against medical advice, financial constrains, physical assasults, poor family support and other social problems which are very difficult to express by the elderly especially abuse. The result is consistent with the findings of ${ }^{18}$ the presences of social problems among the elderly is as a result of the inability of government to cope with the regular payment of pension to retiree, inadequate social services and health facilities to cater for the need of an ageing population. Okoye ${ }^{25}$ reported that, decline in the economy, gradual disintegration of the extended family system, unemployment, increasing female employment to complement family income as well as rural-urban migration contributed to the noticeable decline in the level of care provided by the family in recent times. Medical care specifically for the elderly is not easily accessible as older persons cannot afford quality medical care; due to geographical distance to get these services make it difficult if not impossible for many older persons (Apt, 1995). Neglect of the elderly is gradually evolving, but it is also regarded as an abomination in the Nigeria society as there is reporting channel Ajomale. ${ }^{26} \mathrm{He}$ further explained that, aside from the provision of the criminal code related to crimes of violence and assault there is yet no law on elder abuse.

\section{Conclusion and recommendation}

In conclusion this study has shown that the health status of the elderly was poor. The low social economic status among the respondents had a negative impact on their health status as well as their health seeking behaviour. The importance of emotional support, economic and information support can be deduced from the fact that spending money or giving information as to health and source of better income does not solve the problem of the elderly because these aged entities also need love, care, affection and a feeling of belongingness. Lack of social support for the aged causes in them depression, anxiety and psychosomatic symptoms because they feel unwanted.

There is need to strategize implementation of Geriatric Health Insurance Scheme, recreational and rehabilitation facilities for the elderly within the hospital and their community is also very important to improve their physical, social and psychological well being.

\section{Acknowledgements}

None.

\section{Conflict of interest}

Author declares there is no conflict of interest in publishing the article.

\section{References}

1. Ajomale O. Evaluation Report of African Gerontological Society. Oxford Institute of Population Ageing, Nigeria; 2013.

2. http://www.who.int/ageing/en/ Accessed 1 July 2013

3. Hagestad G, Dannefer D. Concepts and theories of aging. Beyond microfication in social science approaches. Handbook of aging and the social sciences. 2001.

4. http://www.who.int/ageing/publications/global_health.pdf

5. Nigeria Federal Ministry of Health. National policy on the care and wellbeing of the elderly. Federal Ministry of Health, Nigeria; 2003.

6. United States. Public Health Service. Office of the Surgeon General Mental Health. A report of the Surgeon General. NIMH, USA; 1990. 
7. Oyinlola O. Effect of Social Support Systems on the psychosocial wellbeing of the elderly in Old people's home in Ibadan. Unpublished Masters of Social Work Thesis. Ibadan; 2015.

8. Singh R. Psychosocial Problems. An Issue among the Elderly in Kathmandu, International Journal of Health Sciences and Research, Nepal; 2013. p. 2249-9571.

9. Laura EB. Development through the Lifespan. Allyn and Bacon, USA; 2012. p. $155-608$.

10. Cox SO, Abramson U, Hollon I. Later Life The Relatives of Aging. Prentice- Hall, Inc. New Jersey, USA; 2012.

11. Kennedy D. Old age can be made happy. Social Welfare. 2006;21(2):9-10.

12. Balwin, Chiu, Blazer AK. Social psychological theories and their application to aging from individual to collective. Handbook of Theories of Aging. Springer. 2003. p. 209-226.

13. http://www.who.int/mental health/prevention/suicide/suicideprevent/en/ index.html .

14. Vasiliadis HM, Dionne PA, Préville M, et al. The excess healthcare costs associated with depression and anxiety in elderly living in the community. Am J Geriatric Psychiatry Jun. 2013;21(6):536-548.

15. Susan M. Ageing, the Individual and Society, 10th ed. Cengage, USA; 2011. p. 6-7.

16. Georg LK. Well-being. A multidimensional Examination of family caregivers of Demented Adults. The Gerontologist. 2013;26:253-259.

17. Okoye UO. Community-Based Care for Home Bound Elderly Persons In Nigeria. A policy Option. International Journal of Innovative Research in Science, Engineering and Technology. 2013;2(12):7086-7089.

18. Aboderin I. Intergenerational Support and Old Age in Africa. Transaction Publisher. New Jersey USA; 2006. p. 222.

19. Mojoyinola JK. Ayangunna JA. Social Work and Welfare in Aged. In Nigeria.Helen O, Moronkola O.A, Egunyomi D.A, editors. The Adults and Aged, Nigeria; 2012. p. 19-29.

20. Waswa HO. Family caregivers. Disability, illness and ageing, Allen \& Unwin, Australia; 2011.

21. Berger KS. The developing person through the life span .Worth Publication. New York; 2005.

22. Merrill SS, Verbrugge LM. Health and disease in midlife. In: SL Willis, D Reid, editors. Life in the middle. Academic Press. San Diego, USA; 2001.

23. Agarwal S, Srivastava S.K. Effect of living arrangement and gender differences on emotional states and self-esteem of old aged persons. Indian Journal of Gerontology. 2002;16:312-320.

24. Kanwar P, Chadha NK. Psycho-social determinants of institution-alized and non institutionalized elderly. An empirical study. Indian Journal of Gerontol. 1998.

25. Okoye UO. Community-Based Care for Home Bound Elderly Persons In Nigeria. A policy Option. International Journal of Innovative Research in Science, Engineering and Technology. 2013;2(12);7086-7089.

26. http://rcllsociology- of-aging.org/system/files/Nigeria\%202007 0.pdf

27. Sharma J, Sidhu R. Differential Stress and Subjective well-being as Determinants of Quality of Life among aged. Indian Journal of Gerontology. 2009;23(2):183.

28. Aboderin I. Modernisation and ageing theory revisited. current explanations of recent developing world and historical Western shifts in material family support for older people. Ageing and Society. 2004;24(01):29-50.
29. Aboderin I. Decline in material family support for older people in urban Ghana. Africa: Understanding processes and causes of change. J Gerontol B Psychol Sci Soc Sci. 2004;59(3):128-137.

30. Acharya P. Senior Citizens and the Elderly Homes. A Survey from Kathmandu. Dhaulagiri Journal of Sociology and Anthropology. 2007;2:211-226

31. (http://www.aagponline.org/prof/facts_mh.asp).

32. Apt NA. Coping with Old Age in a Changing Africa. Arebury Services, England; 1996.

33. Argyle PS. The Status of the elderly in Nepal. A demographic Perspective In Towards Secure Ageing. Proceedings of National Preparation for the Second World Assembly on Ageing. Nepal Participatory Action Network, Nepal; 2007.

34. Asagba, A. Research and the Formulation and Implementation of Ageing. Policy in Africa. The Case of Nigeria. Generations Review. 2005;15(2):39-44

35. Baiyewu O, Bella AF, Adeyemi JD, et al. Health Problems and Social Demographic Findings in Elderly Nigeria. African Journal of Medical Science, Nigeria; 1997.

36. Bruce ML, Ten Have TR, Reynolds III CF, et al. Reducing Suicidal Ideation and Depressive Symptoms in Depressed Older Primary Care Patients. A Randomized Controlled Trial. Journal American Medical Association 2004;291:1081-1091.

37. Bryant AF. A comparative profile of frail elderly persons living alone and those living with others. Journal of Gerontological Social Work. 2011;21(3/4):5-26.

38. Cavanaug JC. Adult development and aging. Califonia Books/Cole Publication, USA; 1993.

39. Cumming E, Henry WE. Growing Old. Basic Books, New York, USA; 1961

40. European Communities. Mental Health and Well-Being in Older People - Making it Happen. Conclusions from the Thematic Conference. Luxembourg. European Communities. 2010.

41. Help Age International. Forgotten Families. Older people caring for orphans or vulnerable children affected by HIV/AIDS. London. Help Age International. 2011.

42. Help Age International (HAI) Age and security. How social pensions can deliver effective aid to poor older people and their families. London. Help Age International. 2004.

43. Kyomen HH, Whitfield TH. Psychosis in the Elderly. American Journal of Psychiatry. 2012;166(2):146-150.

44. Lee K, Herrera C, L R Lee, et al. Japan Seeking ' A Place Where One Belongs". Elderly Korean Immigrant Women Using Day Care Services. Journal of Transcultural Nursing. 2012;23(4):351-358.

45. National Association Social Worker. Caregiving for Older Adults Washington, USA; 2010.

46. National Population Commission. Population Census of the Federal Republic of Nigeria. Preliminary Report, Nigeria; 2006.

47. http://www.unfpa.org/webdav/site/global/shared/swp/2012/EN SWOP2012 Report.pd Accessed, 20.05.2013

48. United Nations Development Programme (UNDP). Human Development Report. New York, USA; 2004.

49. United States. Public Health Service. Office of the Surgeon General Mental Health. A report of the Surgeon General. NIMH, USA; 1999.

50. http://apps.who.int/iris/bitstre 
51. http://www.who.int/ageing/publications/global_health.pdf

52. Retrieved from http://www.who.int/ageing/en/

53. Okoye UO. The erosion of traditional forms of care for the elderly and its implication for the elderly in Nigeria. In: Omoluabi, E Makiwane, editors. Africa; 2004. p. 224-236.
54. Okoye UO. Family care-giving for ageing parents in Nigeria. gender differences. cultural imperatives and the role of education. International Journal of Education and Ageing. 2012;2(2):139-154.

55. Schulz J. The Economics of Aging. Belmant, Wadsworth, USA; 1980.

56. Kyomen HH, Whitfield TH. Psychosis in the Elderly. American Journal of Psychiatry. 2012;166(2):146-150. 